\title{
Acute cardiovascular complications in patients with diabetes and hypertension: management consideration for minor oral surgery
}

\author{
Ajinath Nanasaheb Jadhav, Pooja Raosaheb Tarte \\ Department of Dentistry, Jamia Islamia Ishaatul Uloom (JIIU)'s Indian Institute of Medical Science \& Research \\ Medical College, Jalna, India
}

\begin{abstract}
J Korean Assoc Oral Maxillofac Surg 2019;45:207-214)
Objectives: Medically compromised patients often fear required dental surgical procedures that can increase the risk of medical emergency when combined with reduced tolerance for stress. A stress reduction protocol (SRP) helps doctors minimize treatment-related stress and improves patient management with minimum complications. Diabetes and co-morbid hypertension carry 4-fold risk of aggravation of cardiovascular emergencies and 7.2-fold risk of mortality. Diabetic neuropathy can result in difficult diagnosis of myocardial infarction and reduces chances of surviving a myocardial infarction compared with a non-diabetic person. The aim of the study was to assess the feasibility of a protocol for management of patients having both diabetes and hypertension who required minor oral surgery to minimize the rate of cardiovascular emergencies.

Materials and Methods: A prospective study was conducted in 140 patients having both diabetes and hypertension who required minor oral surgical procedures. A systematic approachable protocol was designed for management of such patients.

Results: Among 140 patients, 6 patients (4.3\%) had cardiovascular complications, while 3 patients (1 with syncope and 2 with hypertension) did not require any intervention other than observation. Two patients were managed with aspirin and nitroglycerin, and 1 patient had possible myocardial infarction (overall incidence $0.7 \%$ ) with chest pain, S-T segment elevation on electrocardiogram, and troponin level of $0.60 \mathrm{ng} / \mathrm{mL}$.

Conclusion: The proposed protocol helps to improve management of patients having both diabetes and hypertension. We recommend that patients with uncontrolled diabetes and uncontrolled hypertension and/or patients having history of cardiovascular complication should be treated in a medical facility with a readily available cardiology unit. This facilitates prompt response to emergency and instant implementation of treatment, helping to reduce morbidity and mortality.
\end{abstract}

Key words: Diabetes, Hypertension, Cardiovascular complications, Oral surgery

[paper submitted 2018. 10. 21 / revised 2018. 12. 9 / accepted 2018. 12. 16]

\section{Introduction}

Medically compromised patients often fear dental treatment, particularly that involving a surgical procedure that can increase the risk of a medical emergency when combined with their reduced tolerance for stress. A stress reduction protocol (SRP) helps doctors minimize treatment-related

\author{
Ajinath Nanasaheb Jadhav \\ Department of Dentistry, Jamia Islamia Ishaatul Uloom (JIIU)'s Indian \\ Institute of Medical Science \& Research Medical College, Warudi, \\ Tq.Badnapur, Jalna 431202, India \\ TEL: +91-9823460440 FAX: +91-02482-222515 \\ E-mail: drajinathjadhav@gmail.com \\ ORCID: https://orcid.org/0000-0002-2415-2418
}

(c) This is an open-access article distributed under the terms of the Creative Commons Attribution Non-Commercial License (http://creativecommons.org/ licenses/by-nc/4.0/), which permits unrestricted non-commercial use, distribution, and reproduction in any medium, provided the original work is properly cited.

Copyright (C) 2019 The Korean Association of Oral and Maxillofacial Surgeons. All rights reserved. stress and improves patient management in both fearful and medically compromised patients, with minimum complications ${ }^{1}$. The most commonly followed SRP in dentistry is that described by McCarthy².

Diabetes mellitus (DM) alone tends to have high risk for cardiovascular emergency due to accelerated and more extensive coronary atherosclerotic lesion compared with nondiabetic patients ${ }^{3}$. A meta-analysis of 102 prospective studies showed that DM confers two-fold higher risk for coronary heart disease, major stroke, and death ${ }^{4}$.

The risk of cardiovascular disease is higher when patients also have hypertension (HPTN), with an approximately 4 times higher risk than nondiabetic and non-hypertensive patients $^{3,5}$. In follow-up studies, diabetic patients without prior myocardial infarction (MI) have similar risk for fatal coronary heart disease to nondiabetic patients with prior MI. The Framingham cohort study showed that much of this excess 
risk is attributable to coexistent HPTN in diabetic individuals $^{6}$. Diabetes with blood pressure acts as a double-edged sword, and presence of HPTN is responsible for a 7.2-fold increase in mortality in patients with diabetes ${ }^{7,8}$.

Therefore, diabetic patients with concomitant HPTN carry a high risk of aggravation of emergencies like angina, rise in blood pressure, and MI either during a procedure in the dental office or postoperatively at home. This risk demands additional close observation compared to a patient with diabetes or HPTN alone. Moreover, when an emergency occurs in the dental office, medical service is required, and this carries a risk of delay in treatment. Under such conditions, prompt diagnosis and immediate treatment are mandatory, especially when a patient is medically compromised. The goal of such an operation is prevention, identification, and immediate implementation of treatment of cardiovascular complication to reduce morbidity and mortality. Dentists are in a dilemma whether to operate on such patients or to refer the patients to a higher care centre where an intensive care unit is available.

The aim of the study was to establish a separate protocol for management of patients having both DM and HPTN who required minor oral surgery to minimize rates of cardiovascular emergencies and complications. The protocol comprises a combination of various protocols for DM and HPTN and the individual experience of senior oral and maxillofacial surgeons.

\section{Materials and Methods}

A prospective study was carried out from June 2013 to June 2017 at Aurangabad, Maharashtra, India, involving 140 patients diagnosed with both DM and HPTN who required minor oral surgical procedures including extraction of multiple teeth, removal of impacted tooth, drainage of maxillofacial abscesses, alveoloplasty, and placement of one or two implants. A protocol was established for management of such patients based on modification of previous studies.
The following three-step protocol was implemented for management of patients with diabetes and HPTN requiring minor oral surgery.

Step 1: Categorization of patient. This simplifies understanding of risk and reclassifying patients per American Society of Anesthesiologist (ASA) physical status.(Tables 1, 2) Categorization also assists in deciding whether a procedure can safely be performed in an isolated dental clinic or requires admission to a hospital with an intensive care unit.

We hypothesise that patients with both uncontrolled diabetes and HPTN and patients with history of any cardiovascular complications irrespective of blood sugar level and blood pressure should be hospitalized where dental and intensive care units are available. The presence of an expert intensivist to treat cardiovascular complication facilitates better and early management of patients. Admitted patients were observed for 24 hours after surgery to minimize post-complication morbidity and mortality.

Step 2: Follow the general guidelines of the protocol. General guidelines to be followed:

1) Preoperative

- Perform medical consultation

- Laboratory investigation

- Complete blood count

- Bleeding time: should not be more than 18 seconds.

- Prothrombin time and international normalized ratio (INR): should be within a range of 2.5 to 3.5 .

- Blood glucose level: recommended blood sugar level should be equal to or less than $200 \mathrm{mg} / \mathrm{dL}$.

- Consider use of prophylactic antibiotics for elective procedures and therapeutic antibiotics for infections.

- Early morning appointments

- Consider use of tranquilizers one day before and/or 2 hours prior to the procedure.

- Explain the procedure, its outcomes, probable complications, and management.

Table 1. Recommended American Society of Anaesthesiologists (ASA) physical status classification of patient having both diabetes mellitus (DM) and hypertension (HPTN)

\begin{tabular}{|c|c|c|c|}
\hline Group & Category of patient & $\begin{array}{c}\text { ASA physical } \\
\text { status classification }\end{array}$ & $\begin{array}{c}\text { Recommended } \\
\text { ASA physical status }\end{array}$ \\
\hline Group 1.1 & Patients with both controlled DM and HPTN & ASA-2 & ASA-3 \\
\hline Group 1.2 & Patients with controlled HPTN but uncontrolled DM & ASA-3 & ASA-3 \\
\hline Group 1.3 & Patients with controlled DM but uncontrolled HPTN (stage-II) & ASA-3 & ASA-4 \\
\hline Group 1.4 & Patients with both uncontrolled DM and HPTN & ASA-3 & ASA-4 \\
\hline Group 2 & Patients with history of cardiovascular complications attributable to DM and HPTN & ASA-4 & ASA-4 \\
\hline
\end{tabular}

Ajinath Nanasaheb Jadhav et al: Acute cardiovascular complications in patients with diabetes and hypertension: management consideration for minor oral surgery. J Korean Assoc Oral Maxillofac Surg 2019 
Table 2. Criteria for categorization of patients with both diabetes mellitus (DM) and hypertension (HPTN) and specific instructions to follow during a minor oral surgical procedure

\begin{tabular}{|c|c|c|c|}
\hline Group & Description & Criteria & $\begin{array}{l}\text { Specific instructions for each group in } \\
\text { addition to a general protocol }{ }^{1}\end{array}$ \\
\hline \multirow[t]{4}{*}{ Group 1} & $\begin{array}{l}\text { 1. Patients with both controlled } \\
\text { DM and HPTN }\end{array}$ & $\begin{aligned} \mathrm{BSL} & <200 \mathrm{mg} / \mathrm{dL} \\
\mathrm{BP} & <120 / 80 \mathrm{mmHg}\end{aligned}$ & - Procedure can be performed in a dental clinic. \\
\hline & $\begin{array}{l}\text { 2. Patients with controlled HPTN } \\
\text { but uncontrolled DM }\end{array}$ & $\begin{array}{l}\text { BSL }>200 \mathrm{mg} / \mathrm{dL}, \\
\text { BP up to } 159 / 99 \mathrm{mmHg}\end{array}$ & $\begin{array}{l}\text { - Procedure can be performed in a dental clinic. } \\
\text { - Elective procedures should be postponed until control of } \\
\text { sugar level. } \\
\text { - Emergency procedures can be performed with physician } \\
\text { consent (physicians may alter the dosage of oral } \\
\text { hypoglycaemic agent or insulin). }\end{array}$ \\
\hline & $\begin{array}{l}\text { 3. Patients with controlled DM } \\
\text { but uncontrolled HPTN }\end{array}$ & $\begin{aligned} \mathrm{BSL} & <200 \mathrm{mg} / \mathrm{dL} \\
\mathrm{BP} & >159 / 99 \mathrm{mmHg}\end{aligned}$ & $\begin{array}{l}\text { - Procedure can be performed in a dental clinic. } \\
\text { - Elective procedures should be postponed until control of } \\
\text { blood pressure below } 159 / 99 \mathrm{mmHg} \text {. } \\
\text { - Emergency procedures can be performed under } \\
\text { hospitalization and supervision of an intensivist. }\end{array}$ \\
\hline & $\begin{array}{l}\text { 4. Patients with both uncontrolled } \\
\text { DM and HPTN }\end{array}$ & $\begin{array}{l}\mathrm{BSL}>200 \mathrm{mg} / \mathrm{dL} \\
\mathrm{BP}>159 / 99 \mathrm{mmHg}\end{array}$ & $\begin{array}{l}\text { - Hospitalize the patient and perform the procedure under } \\
\text { supervision of an intensivist. }\end{array}$ \\
\hline Group 2 & $\begin{array}{l}\text { Patients with history of cardiovascular } \\
\text { complications attributable to DM } \\
\text { and HPTN }\end{array}$ & $\begin{array}{l}\text { Complications such as myocardial } \\
\text { infarction, cerebrovascular } \\
\text { stroke within last } 6 \text { months or } \\
\text { earlier and patients with } \\
\text { compromised cardiac function } \\
\text { like left ventricular failure, } \\
\text { fibrillation, congestive cardiac } \\
\text { failure irrespective of their } \\
\text { status of controlled BP and } \\
\text { sugar level }\end{array}$ & $\begin{array}{l}\text { - Hospitalize the patient and perform the procedure under } \\
\text { supervision of an intensivist. } \\
\text { - Use of antiplatelets like aspirin or clopidogrel or both } \\
\text { does not need to be stopped. } \\
\text { - Use of heparin must be stopped six hours before surgery } \\
\text { and can be reinstituted after surgery. } \\
\text { - In case patient is under oral anticoagulants therapy like } \\
\text { warfarin, surgical procedure can be performed safely if } \\
\text { international normalised ratio is within the range of } 2 \text { to } \\
3.5 \text {. } \\
\text { - Use of a local haemostatic agent like ethamsylate, } \\
\text { botropause, abgel, pressure pack, or tight sutures must } \\
\text { be considered. }\end{array}$ \\
\hline
\end{tabular}

(BSL: blood sugar level, BP: blood pressure)

${ }^{1}$ Specific instructions for each group are further described in detail in the Discussion section.

Ajinath Nanasaheb Jadhav et al: Acute cardiovascular complications in patients with diabetes and hypertension: management consideration for minor oral surgery. J Korean Assoc Oral Maxillofac Surg 2019

2) Intraoperative guidelines

- Monitor and record vital signs, e.g., pulse rate, blood pressure, respiratory rate

- Cautious use of local anaesthetic with adrenaline (preferably $1: 180,000$ or $1: 200,000$ )

- Adequate pain control

- Consider use of local haemostatic agents like sutures, pressure pack, absorbable gel, and gelatine sponges.

- Length of procedure must not exceed more than 45 minutes.

\section{3) Postoperative}

- Monitor and record vital signs

- Explain proper postoperative instructions to patient and accompanying person.

- Explain potential postoperative systemic complications attributable to DM and HPTN and informing the hospital in case any cardiovascular emergency arises.

- Consider the use of local haemostatic gargle of ethamsyl- ate or tranexamic acid.

Step 3: Follow the specific instructions for each group in addition to the general protocol.(Table 2)

All patients were managed with this protocol and were observed perioperatively for incidence of cardiovascular complications and time of treatment.

\section{Results}

A total of 140 patients including 86 males and 54 females and with a mean age of 51.20 years was involved in the study. Among 140 patients, 6 patients $(4.3 \%)$ had cardiovascular complications, while 3 ( 1 with syncope and 2 with HPTN) did not require intervention other than observation. Two patients with chest pain attributed to anginal pain were managed with aspirin and nitroglycerine, as electrocardiogram (ECG) changes suggestive of MI were not seen. One patient had a possible MI (overall incidence $0.7 \%$ ) with chest pain, S-T segment elevation on ECG, and troponin level of 0.60 
Table 3. Incidence of cardiovascular complications occurring during minor surgical procedures in patients with both diabetes mellitus (DM) and hypertension (HPTN)

\begin{tabular}{|c|c|c|c|}
\hline Group & Category & $\begin{array}{l}\text { No. of } \\
\text { patients }\end{array}$ & Complications occurred (No. of patients) \\
\hline \multirow[t]{5}{*}{ Group 1} & $\begin{array}{l}\text { 1. Patients with both controlled DM and HPTN } \\
(\mathrm{BSL}<200 \mathrm{mg} / \mathrm{dL}, \mathrm{BP}=120 / 80 \mathrm{mmHg})\end{array}$ & 31 & $\begin{array}{l}\text { Syncope (1) } \\
\text { (recovered after } 5 \text { minutes kept under observation, procedure } \\
\text { continued without any further complication) }\end{array}$ \\
\hline & $\begin{array}{l}\text { 2. Patients with controlled HPTN but uncontrolled DM } \\
\text { (BSL <200 mg/dL, BP up to } 159 / 99 \mathrm{mmHg} \text { ) }\end{array}$ & 40 & $\begin{array}{l}\text { Raised blood pressure (1) } \\
\quad \text { (observation showed normotensivity) }\end{array}$ \\
\hline & $\begin{array}{l}\text { 3. Patients with controlled DM but uncontrolled HPTN } \\
\text { (BSL <200 mg/dL, BP up to } 159 / 99 \mathrm{mmHg} \text { ) }\end{array}$ & 26 & $\begin{array}{l}\text { Raised blood Pressure (1) } \\
\quad \text { (observation showed normotensivity) }\end{array}$ \\
\hline & & & $\begin{array}{l}\text { Mild chest pain relieved on nitroglycerine (1) } \\
\text { (needed 24-hour admission, ECG changes were not seen) }\end{array}$ \\
\hline & $\begin{array}{l}\text { 4. Patients with both uncontrolled DM and HPTN } \\
(\text { BSL }>200 \mathrm{mg} / \mathrm{dL}, \mathrm{BP}>159 / 99 \mathrm{mmHg})\end{array}$ & 24 & $\begin{array}{l}\text { Severe chest pain (1) } \\
\text { (patient was treated by an intensivist. ECG changes were } \\
\text { noted with S-T segment elevation, suggestive of myocardial } \\
\text { infarction, troponin level } 0.6 \mathrm{ng} / \mathrm{mL} \text { ) }\end{array}$ \\
\hline Group 2 & $\begin{array}{l}\text { Patients with history of cardiovascular complications } \\
\text { attributable to DM and HPTN }\end{array}$ & 19 & $\begin{array}{l}\text { Mild Chest pain relieved on nitroglycerine (1) } \\
\text { (needed 24-hour observation but ECG changes were not seen) }\end{array}$ \\
\hline Total & & 140 & 6 \\
\hline
\end{tabular}

(BSL: blood sugar level, BP: blood pressure, ECG: electrocardiogram)

Ajinath Nanasaheb Jadhav et al: Acute cardiovascular complications in patients with diabetes and hypertension: management consideration for minor oral surgery. J Korean Assoc Oral Maxillofac Surg 2019

$\mathrm{ng} / \mathrm{mL}$ and required thrombolysis and further treatment by an intensivist.(Table 3)

Cardiovascular complication occurred in nearly all types of minor surgical procedure, but the most significant complication of chest pain occurred during impacted tooth removal and abscess drainage.(Table 4) All 3 patients who had chest pain had been admitted for surgery performed under the observation of an intensivist, facilitating immediate treatment. This helped to prevent further adverse complications. Among patients who had chest pain, 2 recovered after sublingual nitro-glycerine and aspirin, while 1 showed ECG changes and was diagnosed with MI. Further treatment was performed by an intensivist.

\section{Discussion}

Uncontrolled diabetes leads to acute or chronic complications attributed to blood glucose concentration. Abnormally high blood glucose can have life-threatening impact if it triggers conditions like diabetic ketoacidosis in type-1 and type2 diabetes and hyperosmolar coma in type- 2 diabetes. Abnormally low glucose can occur in all types of diabetes and may result in seizure and loss of consciousness and can occur after skipping a meal or exercising more than usual or if the dosage of hypoglycaemic agents is too high ${ }^{9}$. Chronic complications of diabetes include coronary insufficiency and stroke ${ }^{10}$.

Chronic HPTN precedes the onset of vascular changes in the kidney, heart, and brain and leads to clinical complica-
Table 4. Number of patients who underwent a minor surgical procedure, patient category, and complications

\begin{tabular}{|c|c|c|c|}
\hline $\begin{array}{l}\text { Surgical } \\
\text { procedure }\end{array}$ & $\begin{array}{l}\text { No. of } \\
\text { patients }\end{array}$ & $\begin{array}{l}\text { Cardiovascular } \\
\text { complication } \\
\text { (No. of patients) }\end{array}$ & $\begin{array}{l}\text { Category } \\
\text { of patient }\end{array}$ \\
\hline Alveoloplasty & 32 & Syncope (1) & Group 1.1 \\
\hline $\begin{array}{l}\text { Multiple tooth } \\
\text { extraction }\end{array}$ & 46 & $\begin{array}{l}\text { Raised blood pressure (1) } \\
\text { Raised blood pressure (1) }\end{array}$ & $\begin{array}{l}\text { Group } 1.2 \\
\text { Group } 1.3\end{array}$ \\
\hline $\begin{array}{l}\text { Impacted tooth } \\
\text { removal }\end{array}$ & 26 & $\begin{array}{l}\text { Mild chest pain (1) } \\
\text { Severe chest pain (1) }\end{array}$ & $\begin{array}{l}\text { Group } 1.3 \\
\text { Group } 1.4\end{array}$ \\
\hline Implant placement & 17 & - & - \\
\hline Abscess drainage & 19 & Mild chest pain (1) & Group 2 \\
\hline Total & 140 & 6 & \\
\hline
\end{tabular}

Ajinath Nanasaheb Jadhav et al: Acute cardiovascular complications in patients with diabetes and hypertension: management consideration for minor oral surgery. J Korean Assoc Oral Maxillofac Surg 2019

tions including renal failure, stroke, coronary insufficiency, MI, congestive heart failure, dementia, encephalopathy, and blindness ${ }^{11}$.

Patients suffering from DM and HPTN must be considered unique due to following factors. About two-thirds of patients with diabetes have high blood pressure and have 2 to 4 -fold greater risk for MI and stroke than persons without diabetes. These patients have less chance of surviving a MI than a typical non-diabetic person ${ }^{12,13}$.

Diabetes with blood pressure acts as a double-edged sword, and such patients carry significant high risk for premature microvascular and macrovascular complications. According to a recent study, presence of HPTN is responsible for 7.2-fold increase in mortality in patients with diabetes ${ }^{7}$. Further, autonomic neuropathy may predispose to infarction and result in 
atypical presenting symptoms in diabetic patients, complicating diagnosis and delaying treatment. The clinical course of MI is frequently complicated and carries a higher mortality rate in diabetic patients ${ }^{8}$.

ASA physical status classification is universally followed to identify risk in medically compromised patients. Normally, a patient with type-2 diabetes well controlled with oral hypoglycaemic agents and diet is categorised as ASA-2, and those under control with insulin and diet are categorised as ASA$3^{14}$. Owing to increased risk and severity of cardiovascular complications, we propose that a patient having well controlled diabetes with HPTN should be categorised as ASA-3. The category of patient with both uncontrolled diabetes and HPTN should be considered ASA-4, a patient with severe systemic disease with constant threat to life. In addition, a patient with angina, previous MI, cerebrovascular accident, and other cardiovascular complications should be categorised as ASA-4.(Table 4)

Specific guidelines for each group and rationale are discussed below in detail.

\section{Group 1.1: Patients with controlled DM and HPTN}

These patients should be regarded as ASA-3, and general guidelines should be followed.

\section{Group 1.2: Patients with controlled HPTN but uncontrolled DM}

These patients should be considered ASA-3.

Elective procedures should be postponed until control of sugar level.

Emergency procedures can be performed with physician consent. Physicians may alter the dosage of oral hypoglycaemics or insulin.

\section{Group 1.3: Patients with controlled DM but uncontrolled HPTN}

Classified as ASA-3 for elective procedures but must be considered as ASA-4 for emergency procedures.

Elective procedures can be postponed until control of blood pressure below 159/99 $\mathrm{mmHg}$.

Emergency procedures can be performed if blood pressure is in stage 1 (systolic $\leq 159$ and diastolic $\leq 99$ ) using general guidelines.

A blood pressure measurement of $180 / 110 \mathrm{mmHg}$ as the absolute cut-off for any dental treatment has been well published ${ }^{15}$. Studies have shown no increased risk for adverse outcomes for patients undergoing treatment with blood pressure $<180 / 110 \mathrm{mmHg}^{16}$.

However, we hypothesise and suggest that optimum level of blood pressure for minor oral surgical procedure should be $<160$ systolic and $<99 \mathrm{mmHg}$ diastolic because such patients require judicious monitoring ${ }^{7}$.

We propose hospitalization of such patients with an available intensive care unit along rather than undertaking procedures in an isolated dental clinic.

\section{Group 1.4: Patients with uncontrolled diabetes and uncontrolled HPTN}

These patients must be categorised as ASA-4 because they carry the highest risk of aggravation of cardiovascular complications.

Elective procedures can best be postponed until control of both DM and HPTN.

Emergency procedures: such patients are highly prone for systemic complications such as diabetic ketoacidosis, unconsciousness due to low or high blood glucose concentration, stroke, angina, or acute MI. In addition, there are chances of local surgical complications such as excessive primary or secondary haemorrhage and delayed wound healing ${ }^{17}$. We strongly advocate hospitalizing such patients in a facility with a both a dental clinic and intensive care unit.

\section{Group 2: Patients with diabetes and coexistent HPTN along with complications}

Such patients have a compromised cardiovascular system with a constant threat of aggravation and further complications. These patients previously experienced complications like angina pectoris, MI and other cardiomyopathy, cerebrovascular accidents, or target organ complications of kidney or retina. In addition, they are on multiple drug therapies such as insulin, oral hypoglycaemics, or a combination of both; antihypertensives; anticoagulants; and antiplatelet drugs. Patient compliance must be considered while prescribing drugs for such patients.

According to ASA classification, a patient with MI or cerebrovascular accident 6 months prior without no or minimal residual damage is considered as ASA-3, but concurrent HPTN and diabetes increases risk of cardiovascular complications. Thus, we hypothesise that such patients must be 
considered as ASA-4, irrespective of blood sugar and blood pressure.

We recommend that minor oral surgical procedures be performed after hospitalization and under observation of an intensivist because of constant threat of life. The following factors must be considered when treating these patients.

\section{1) Time of surgery}

The safest time to perform a dental surgical procedure is 6 months or more following MI or stroke. In emergencies, such a procedure can be performed as early as 30 days following $\mathrm{MI}^{18}$.

\section{2) Pain control}

If pain control is required, it should be as conservative as possible and directed primarily towards pain relief and infection control ${ }^{19}$.

Nonsteroidal anti-inflammatory drugs must be prescribed cautiously according to a finding that extensive use of rofecoxib, celecoxib, and diclofenac increases the risk of acute MI, but similar use of ibuprofen and naproxen does not ${ }^{20}$.

\section{3) Local anaesthesia}

A local anaesthetic without adrenaline is preferable, but if a vasoconstrictor is required, a patient taking a nonselective beta blocker can safely be given up to $0.036 \mathrm{mg}$ epinephrine at one appointment. In addition, modest quantities of vasoconstrictor $(1: 200,000)$ can be used safely even in high risk patients when accompanied by oxygen, sedation, nitro-glycerine, and excellent pain control measures ${ }^{18,19}$. When injecting local anaesthetic, a double aspiration technique should be performed to prevent intravascular injection.

\section{4) Patients on warfarin}

In patients on anticoagulant therapy like warfarin, minor oral surgery can be performed without altering or stopping warfarin provided that INR is within the therapeutic range of 2 to $3.5^{21}$. There is a little or no indication for altering anticoagulation therapy before minor oral surgical procedures when the patient's INR is $<3.5^{19}$.

\section{5) Patients on heparin}

Heparin should be stopped six hours prior to surgery and can be reinstituted after surgery until a desirable INR level has been reached ${ }^{22}$.

\section{6) Patients on antiplatelet drugs}

All patients with coronary artery disease are on antiplatelet therapy, either aspirin alone or dual antiplatelet therapy (e.g., aspirin and clopidogrel), which increases the risk of excessive bleeding during surgical procedure. Discontinuation of antiplatelet therapy has been significantly associated with adverse cardiac events, such as MI or death, especially after placement of a bare metal stent or drug-eluting stents. As the risk of bleeding from anything other than highly invasive oral surgery is small and post-extraction bleeding is relatively easy to manage, antiplatelet therapy should not be discontinued $^{23}$. Lee ${ }^{24}$ systematically described the management of patients on antiplatelet drugs such as oral aspirin alone, dual antiplatelet therapy, and oral or injectable anticoagulants. He also advised at the consensus meeting on antithrombotic agents held on March 24, 2018 at Seoul National University Dental Hospital by the Korean Association of Oral and Maxillofacial Surgeons that a future consensus paper on dental management of patients on antithrombotic medication is needed. In our study, we followed similar guidelines in medically compromised patients undergoing minor oral surgical procedures like multiple tooth removal, implant placement, and third molar surgery associated with high risk for bleeding. Our study revealed promising results of management of patients on antithrombotic treatment, favourable to the review study of $\mathrm{Lee}^{24}$. In such patients, the use of local haemostatic measures such as placing gelatine sponges, oxidised cellulose, or suturing gauze sponge for pressure packs and postoperative tranexamic acid mouth rinses are recommended.

There is little study on dental management of patients with both diabetes and HPTN. These 2 conditions contribute to the most frequent cardiovascular emergencies, and their concurrence is the largest risk factor of aggravation of emergencies.

McCarthy ${ }^{25}$ stated that implementation of a complete system of physical evaluation for all prospective dental patients could prevent up to $90 \%$ of life-threatening situations. The remaining $10 \%$ would occur despite preventive efforts.

Yoon et al. ${ }^{26}$ in 2001 evaluated the influences of epinephrine and pain on changes of blood pressure and pulse rates in mandibular third molar removal. A total of 80 patients with medically compromised condition was selected. Forty patients were treated with $2 \%$ lignocaine with 1:100,000, and the others were treated with lignocaine without adrenaline. Digital monitoring of blood pressure and heart rate occurred perioperatively. He concluded that local anaesthetic with epinephrine is better at decreasing pain and preventing severe elevation of systolic blood pressure than local anaesthetic 
without epinephrine ${ }^{25}$. Similar findings were reported in our study, where blood pressure was elevated only in 2 patients ${ }^{26}$.

In the current study with a modified SRP for patients with both diabetes and HPTN, the incidence of cardiovascular emergencies was reduced by up to $4.3 \%$, with no patient death. Interestingly, all significant emergencies occurred in patients who were hospitalized for procedures performed under observation of an intensivist. This facilitated early identification and immediate implementation of treatment.

\section{Conclusion}

We conclude that diabetic patients with concurrent HPTN carry 4-fold risk of aggravation of cardiovascular emergencies and 7.2-fold risk of mortality and have less chance of surviving a MI than a typical non-diabetic person.

We also conclude that a systematically designed protocol for these patients helps in proper assessment of risk and close observation of patients, reducing incidence of medical emergencies up to $4.3 \%$. The study recommends that some of these patients with uncontrolled diabetes and uncontrolled HPTN and/or patients having history of cardiovascular complication should be treated in a medical facility with a readily available cardiology unit. Hospitalization of these patients not only helps in reduction of cardiovascular emergencies, but also assists in prompt diagnosis and instant implementation of treatment by an intensivist/cardiologist, thereby reducing morbidity and mortality. The protocol is suggested to offer better management of such patients.

\section{ORCID}

Ajinath Nanasaheb Jadhav, https://orcid.org/0000-00022415-2418

Pooja Raosaheb Tarte, https://orcid.org/0000-0002-8295-4398

\section{Authors' Contributions}

A.N.J. contributed towards study design, data analysis, and manuscript preparation. P.R.T. involved in data collection, co-ordination, and drafting of manuscript. All authors read and approved the final manuscript.

\section{Ethics Approval and Consent to Participate}

Given the non-interventional and descriptive observational nature of the study, approval was exempted by the institu- tional review board. However, all procedures performed in studies involving human participants were in accordance with the ethical standards of the institutional committee, the 1964 Helsinki declaration, and its later amendments or comparable ethical standards.

\section{Conflict of Interest}

No potential conflict of interest relevant to this article was reported.

\section{References}

1. McCarthy FM, Malamed SF. Physical evaluation system to determine medical risk and indicated dental therapy modifications. J Am Dent Assoc 1979;99:181-4.

2. McCarthy FM. Stress reduction and therapy modification. CDA J 1981;9:41-7.

3. Stamler J, Vaccaro O, Neaton JD, Wentworth D. Diabetes, other risk factors, and 12-yr cardiovascular mortality for men screened in the multiple risk factor intervention trial. Diabetes Care 1993;16:434-44.

4. Emerging Risk Factors Collaboration, Sarwar N, Gao P, Seshasai SR, Gobin R, Kaptoge S, et al. Diabetes mellitus, fasting blood glucose concentration, and risk of vascular disease: a collaborative meta-analysis of 102 prospective studies. Lancet 2010;375:221522.

5. Hu G, Jousilahti P, Tuomilehto J. Joint effects of history of hypertension at baseline and type 2 diabetes at baseline and during follow-up on the risk of coronary heart disease. Eur Heart $\mathrm{J}$ 2007:28:3059-66.

6. Haffner SM, Lehto S, Rönnemaa T, Pyörälä K, Laakso M. Mortality from coronary heart disease in subjects with type 2 diabetes and in nondiabetic subjects with and without prior myocardial infarction. N Engl J Med 1998;339:229-34.

7. Cowie CC, Rust KF, Byrd-Holt DD, Eberhardt MS, Flegal KM, Engelgau MM, et al. Prevalence of diabetes and impaired fasting glucose in adults in the U.S. population: National Health And Nutrition Examination Survey 1999-2002. Diabetes Care 2006;29:1263-8.

8. Jacoby RM, Nesto RW. Acute myocardial infarction in the diabetic patient: pathophysiology, clinical course and prognosis. J Am Coll Cardiol 1992;20:736-44.

9. Loewen SL, Haas LB. Complications of diabetes: acute and chronic. Nurse Pract Forum 1991;2:181-7.

10. Chawla A, Chawla R, Jaggi S. Microvasular and macrovascular complications in diabetes mellitus: distinct or continuum? Indian J Endocrinol Metab 2016;20:546-51.

11. Drozdz D, Kawecka-Jaszcz K. Cardiovascular changes during chronic hypertensive states. Pediatr Nephrol 2014;29:1507-16.

12. Nathan DM, Cleary PA, Backlund JY, Genuth SM, Lachin JM, Orchard TJ, et al.; Diabetes Control and Complications Trial/Epidemiology of Diabetes Interventions and Complications (DCCT/ EDIC) Study Research Group. Intensive diabetes treatment and cardiovascular disease in patients with type 1 diabetes. N Engl J Med 2005;353:2643-53.

13. Martín-Timón I, Sevillano-Collantes C, Segura-Galindo A, Del Cañizo-Gómez FJ. Type 2 diabetes and cardiovascular disease: have all risk factors the same strength? World J Diabetes 2014;5:444-70.

14. Haynes SR, Lawler PG. An assessment of the consistency of ASA physical status classification allocation. Anaesthesia 1995;50:1959. 
15. Hogan J, Radhakrishnan J. The assessment and importance of hypertension in the dental setting. Dent Clin North Am 2012;56:73145.

16. Barnes JN, Joyner MJ. Physical activity and cardiovascular risk: 10 metabolic equivalents or bust. Mayo Clin Proc 2013;88:1353-5.

17. Southerland JH, Gill DG, Gangula PR, Halpern LR, Cardona CY, Mouton CP. Dental management in patients with hypertension: challenges and solutions. Clin Cosmet Investig Dent 2016;8:11120.

18. Findler M, Galili D, Meidan Z, Yakirevitch V, Garfunkel AA. Dental treatment in very high risk patients with active ischemic heart disease. Oral Surg Oral Med Oral Pathol 1993;76:298-300.

19. Niwa H, Sato Y, Matsuura H. Safety of dental treatment in patients with previously diagnosed acute myocardial infarction or unstable angina pectoris. Oral Surg Oral Med Oral Pathol Oral Radiol Endod 2000;89:35-41.

20. Jick H, Kaye JA, Russmann S, Jick SS. Nonsteroidal antiinflammatory drugs and acute myocardial infarction in patients with no major risk factors. Pharmacotherapy 2006;26:1379-87.

21. Cintron G, Medina R, Reyes AA, Lyman G. Cardiovascular effects and safety of dental anesthesia and dental interventions in patients with recent uncomplicated myocardial infarction. Arch Intern Med 1986;146:2203-4.

22. Lu SY, Tsai CY, Lu SN, Lin LH. Is alteration of warfarin regimen necessary before dental extractions in Taiwanese patients? Results of a retrospective cohort study. J Dent Sci 2015;10:352-8.

23. Bajkin BV, Urosevic IM, Stankov KM, Petrovic BB, Bajkin IA. Dental extractions and risk of bleeding in patients taking single and dual antiplatelet treatment. Br J Oral Maxillofac Surg 2015;53:3943.

24. Lee JK. Dental management of patients on anti-thrombotic agents. J Korean Assoc Oral Maxillofac Surg 2018;44:143-50.

25. McCarthy FM. Sudden, unexpected death in the dental office. J Am Dent Assoc 1971;83:1091-2.

26. Yoon HJ, Lee SH, Song HC. The influences of epinephrine and pain on the changes of systolic blood pressure and pulse rates in mandibular 3rd molar extraction. J Korean Assoc Oral Maxillofac Surg 2001;27:556-9.

How to cite this article: Jadhav AN, Tarte PR. Acute cardiovascular complications in patients with diabetes and hypertension: management consideration for minor oral surgery. J Korean Assoc Oral Maxillofac Surg 2019;45:207-214. https://doi.org/10.5125/ jkaoms.2019.45.4.207 